\title{
Research on the Affecting Factors and the Countermeasures in Listening Teaching Based on the Cloud Platform
}

\author{
Zhihui Liu and Jiaming Zhong* \\ Xiangnan University \\ jmzhongcn@163.com \\ *The corresponding author
}

\section{Keywords: Listening teaching; Affecting factors; Countermeasures; Cloud platform}

\begin{abstract}
This paper analyzes the listening teaching based on cloud platform, exploring the affecting factors, such as psychological factors, knowledge and skill factors, cultural factor etc. Meanwhile, it puts forward countermeasures like updating teaching beliefs, strengthening knowledge and skills training, promoting the deep integration of information technology and teaching in order to improve the effects of listening teaching.
\end{abstract}

\section{Introduction}

Listening teaching based on cloud platform is to storage the foreign language teaching resource on the server of the cloud platform, which will expand the language input, provide a network teaching and learning environment for both teachers and students and build autonomous learning environment as well. Therefore, students' learning enthusiasm will be enhanced, and the teaching quality will be improved.

Language learning is not only a pure grasp of grammar and vocabulary, but also an up-grading of students' comprehensive qualities of reading, writing, listening and speaking, especially the listening skills. College English Curriculum Requirements puts forward the teaching target of college English is to develop students' English comprehensive application ability, especially the abilities in listening and speaking. According to the statistics of foreign language teaching experts W. M. Rivers and Trmperly, 45\% of the use of language is completed by listening. Therefore, listening plays an extremely important role in daily life and in the skills training. Therefore, it is urgent to explore the affecting factors and countermeasures of listening teaching in the new teaching mode.

\section{Affecting Factors in Listening Teaching}

There are many factors which will affect listening, such as psychological factors, knowledge and skill factors, cultural factor and so on.

Psychological Factors. (1) Anxiety: Anxiety is an important factor that influences language learning. It comes from the negative emotions, such as anxiety, depression, self-doubt, fear and tension. For example, in listening process, when students encounter a new word or phrase, they often think about it for such a long time that they miss the important information of the whole sentence. The fear to new words is one of the characteristics of anxiety. Anxiety sets up a vicious circle of anxiety which makes people be nervous and afraid, leading to poor performance, which in turn worsens performance and causes more anxiety. The pressure from outside, such as examination, competition and the evaluation from other people also can create anxiety. So, how to reduce the negative effects of anxiety, cultivate positive emotion of learners and create a favorable learning psychological state for students are the issues which teachers need to consider.

(2)Characteristics difference: The personality can be divided into two types: introversion and extroversion. Different personality traits affect learning process. "Outward learners actively participate in classroom activities and seek more learning opportunities. They are impressive speakers and are considered to be good at learning language. Introverts are uncommunicative and 
are not actively participate in classroom activities since they are more self-restrained, which seems to be not good at language learning. In fact, extroverts need more outside recognition, from which they can get self-satisfaction and confidence. Inward learners can get the support from themselves and they tend to have strong willpower and sympathy". Therefore, introverts do not necessarily have a high degree of inhibition and they can also be good language learners. Teachers shall pay attention to different learners with different characteristics in the language classroom, adopting correct attitudes and various methods to meet the needs of different students. Hence, the effects of language learning and teaching will be greatly improved.

(3) Self-esteem: Self-esteem as well as anxiety is one of the most important psychological factors in language learning. Self-esteem plays a key role both in cognitive activities and emotional activities. "A large number of studies show that, if students' self-esteem is protected and encouraged, the cognitive activities in learning are the most effective." In real teaching activities, it's easy to find that the learners with the successful experience will continue to motivate themselves to achieve further success; and those who often fail are not willing to participate in learning activities since their self-esteem is gradually damaged, which leads to the final failure. Therefore, teachers shall set different learning objectives to meet the needs of different learners, which may make them confident in the process of achieving the goal and experiencing success.

(4) Motivation: Motivation is another important psychological factor in language learning. Earlier studies divide the learning motivation of a second language into instrumental motivation and integrating motivation. Instrumental motivation refers to learning for the actual needs, such as employment. While integrating motivation emphasizes learners' interests in target language and its culture. In this case, the learners hope to be accepted by the target language society and integrate with the society.

Another classification divides motivation into internal motivation and external motivation: internal motivation comes from strong interest in learning contents or learning tasks; external motivation is from outside influences, such as reward or punishment. To some extent, the internal motivation plays more important role than the external motivation in language learning, since it lasts for a longer time and becomes an important prerequisite for long-term success. In other words, strong interest (the positive psychological factor) will trigger the integrating motivation or internal motivation.

Knowledge and Skill Factors. (1). Phonology: Phonology is the basic unit of language. If learners cannot percept or distinguish the individual sounds clearly and correctly, listening will become difficult. In the fast speech, sound change happens. Lacking the knowledge of the phonology, such as reduction, linking, special explosion, strong forms and weak forms etc. also cause mistakes in listening comprehension. Even stress and rhythm sometimes makes misunderstanding.

(2) Vocabulary: Vocabulary has underestimated effects on listening comprehension. The shortage of vocabulary will bring about listening hurdles or misunderstanding. The focus of the teaching in class should be on helping the students to enlarge their vocabulary as much as possible.

(3) Grammar knowledge: Understanding the grammar is the key to catch the structure of the sentence. Although learners know the meaning of each word in a sentence, if they cannot understand the logic relation and the grammar rules, they may misunderstand the meaning of the sentence.

Cultural Background Knowledge. Listening materials vary from astronomy to geography. If students only pay attention to phonology, grammar and vocabulary literally, ignoring the important connotation transferred by language, it is difficult for them to understand raw materials, the speakers' tone, attitude and intentions precisely.

Information Literacy. The information literacy, the abilities of controlling the computer and the network differs from one to another, which will cause a lot of troubles in listening teaching.

\section{Countermeasures to Improve the Quality of Listening Teaching}

In order to improve the effect of listening teaching in English, the following strategies will be 
adopted, such as dredge information channel, and ensure fluency in language input and output.

Update Ideas. (1)Set up a new concept of students-centered. The focus of teaching not only on students' comprehensiveness and initiative, but also on students' diversity and individuality.

(2) Set up the new concept of teaching, putting more emphasis on the exchanges and interaction between teachers and students. The teaching process is the active interaction between teachers and students. The humanitarian, harmonious, equal relationship between teachers and students will be rebuilt in this way. The teacher plays as a helper, a facilitator, an organizer and an implementer of learning activities who pays attention to the learning process, and provides guidance and feedback for students as well. With the help of the teachers, students carry out their learning activities. Students shall communicate with teachers unceasingly, get the teacher's feedback and put forward problems and so on.

(3) Set up a new concept of learning, promoting autonomous, inquiry and collaborative learning. The change of learning style should be realized actively.

(4) Establish a new talent view and attach great importance to diversified talent training model. Pay attention to examine the degree for students to master the basic knowledge and basic skills, at the same time, examine whether they have the abilities of lifelong learning and collaboration with others, whether they have the innovation spirit and practice ability, which makes them be more suitable for the requirements of economic and social development in the new century.

(5) Set up the concept of people-orientation. Always keep in mind the concept of people-orientation, comprehensively develop all students.

To Strengthen the Knowledge and Skills Training. (1) In terms of improving students' listening, basic knowledge of English language should not be ignored. It is a must to learn and consolidate the basic knowledge of English language in order to lay a solid foundation to improve listening. What's more, lacking language knowledge tend to cause students' psychological anxiety. To learn and consolidate the basic knowledge, it can be started mainly from the three aspects, including phonology, grammar and vocabulary. Taking phonology as an example, some problems in the pronunciation takes time to correct. Thus, students are required to use audio resources on the cloud platform, to imitate, to read and to master. Since lots of students still do not have a solid foundation in grammar, they shall be required to review and consolidate grammatical knowledge by using the resources from cloud platform. For vocabulary, teachers shall not only ask students to make great effort to memory words, the rules of vocabulary such as prefix, suffix, compounds, etc. should be introduced and explained.

Meanwhile, researchers believe that the process of listening comprehension is not pure language information decoding, but a combination of decoding process and significance reconstruction. In the process, the active participation of learners is important. The social cultural background knowledge, pragmatic knowledge and the language knowledge of listeners are also important. In the process of listening comprehension, students will frequently expose to the culture information of the target language. The lack of understanding of the differences between Chinese and Western culture will inevitably affect the discourse understanding. For example, in Unit 46 to Unit 48 of Introduction to Listening 6, all the content are involved in British and American education. Due to the different education system and teaching structure of China and the Western countries, if students have little understand or are not familiar with this knowledge, it is bound to affect the understanding of listening. The public education of each state in the United States is in charge of a school district in the state. The general school district includes a city or a town. Each school district is composed by the staff of the school board which is produced by election. The public school funding comes from the property tax collected from various towns. These background knowledge related to the text materials shall be introduced before listening to make students have a deep understanding to the meanings of the recurring word meanings, such as public school, school district and school board, in order to clear the cultural barriers in listening and to achieve the purpose of improving the level of listening comprehension.

(2) Cultivate students' integrity and repeatability in vocabulary memory. After students enter the college, foreign language teachers shall make them be aware of the need to pay attention to the 
integrity and repeatability of pronunciation, shape and meaning in vocabulary memory. In this stage, dictation is a kind of basic training which cannot be ignored. Dictation is helpful to improve students' ability to distinguish sound and remember their pronunciation. Making full use of listening materials on the cloud platform, teachers can also select some listening materials which are suitable for students in order to eliminate the adverse factors which cause obstacles for listening comprehension due to the inappropriate vocabulary learning methods.

Sometimes students can easily catch a simple sentence and repeat it correctly, while they don't have any idea about it. In this case, teachers must help them and analyze the problems. The efficiency of vocabulary memory involves multiple organs, such as eyes, mouth and brain, which not only stimulate the brain, but also cultivate students' ability of thinking in English. Gradually, students' interests in learning English will be much stronger. So the students' learning motivation will be enhanced greatly.

To Promote the Deep Integration of Information Technology and Language Teaching. It is necessary for both teachers and students to intensify information technology training, to strengthen theoretical study and practice exploration of network so as to constantly improve the information-based education and reasonably use modern education technology. Thus, the classroom teaching will be optimized and the teaching efficiency will be improved. Actively develop, enrich and improve the teaching resources on digital forms or from network, information technology and network space will be fully used in teaching.

To Train the Students' Psychological Quality to Overcome the Psychological Barriers. The process of listening comprehension does not only evaluate students' ability of perception, but also test students' psychological quality. If the students are in the mood for listening, their listening comprehension can truly be achieved. Therefore, teachers had better set up students' self-confidence in the initial stage of listening, that they can achieve the desired results by themselves through a period of training. Students can experience a process of listening while reading, listening after reading, reading after listening. These simulation exercises practice students' psychological endurance, overcome the anxiety in listening process.

To Specify Learning Goals. Teachers shall help students confirm their own subjective desires. And then an integrated, hierarchical, dynamic and incentive study plan will be set out according to student's different level of proficiency in English. Therefore, autonomous learning will be realized.

Foster a Good Learning Atmosphere. Teaching environment shall be bright, comfortable, concise and generous. The teaching facilities shall be good for the interaction and communication between teachers and students. Class members shall be warm and friendly. They will respect, support and trust each other, as well as be responsible for each other. All the students shall be in a positive cooperation and competition learning environment.

Improve Teaching Evaluation Method. For teachers, evaluation is not only an important basis to obtain the feedback, to improve the teaching management and to ensure the quality of teaching, also the effective means for students to adjust their learning strategy, to improve learning methods and to improve learning efficiency. It is necessary to use the scientific evaluation method combining the formative evaluation and the summative evaluation, self-evaluation and peers' evaluation.

\section{Acknowledgement}

Scientific research project of Department of Education Funding of Hunan Province (the application research on the intelligent teaching system based on Web in English listening teaching, item number 12C0901).

\section{References}

[1] M.P. Cao: Chinese Vocational and Technical Education, (2003) No.4, p.29-30.

[2] X.L. Chen: Media in Foreign Language Instruction, (2004) No.5, p.65-72.

[3] L.S. Luo, Z.N.Li and L. Ge: Journal of Tsinghua University, (2001) No.4, p.71-74. 
[4] Y.N. Liu: Journal of Inner Mongolia Normal University (Education science edition), (2005) No.5.

[5] Z.H. Liu: Journal of Qiongzhou University, Vol. 15 (2008) No.4, p.108-109.

[6] X.Q. Qin: Quantitative Data Analysis in the Study of Foreign Language Teaching (Huazhong University of Science and Technology Press, China 2003).

[7] C.M. Wang, L.Lin: Foreign Language Education in China, (2010) No.2, p. 21-28.

[8] Y.Q. Wang, Y.S. Wan: Foreign language teaching and research, (2001) No.2, p.122-126.

[9] X. Zhang, G.Y. Zhao: Modern Foreign Language, (2011) No.2, p.162-170. 